\title{
Ensino Médio Integrado: Desafios da experiência de implementação do Curso Técnico em Dança
}

\section{Integrated High School: Challenges of the experience of implementing the Technical Course on Dancing}

\author{
${ }^{1}$ Mariza da Gama Leite de Oliveira marizagoliva@gmail.com
}

\begin{abstract}
RESUMO
O artigo reflete sobre a relação entre Trabalho e Educação e discute as principais concepções e desafios na implementação do Ensino Médio Integrado, conforme concepções de pesquisadores do campo de formação profissional, que analisam criticamente os decretos 2208/97 e 5154/04, e denunciam sua fragilidade ao criarem o ensino médio integrado apenas como mais uma opção de articulação. Relata a experiência de construção do curso Técnico em Dança integrado, da Fundação de Apoio à Escola Técnica (FAETEC), suas características e principais desafios, dentre os quais a resistência docente. Conclui que somente através do esforço conjunto entre professores, coordenadores e instituições de ensino, para a valorização das diversas fontes de saber que podem emanar da experiência docente, será possível a integração curricular na perspectiva da Escola Unitária, base ideológica que sustenta a concepção desta modalidade de ensino.
\end{abstract}

Palavras-chave: Curso Técnico em Dança. Organização Curricular. Escola Unitária. Aprendizagem Significativa. Saber Docente.

\begin{abstract}
The article reflects on the relation between Work and Education and discusses the main conceptions and challenges in the implementation of the Integrated High School, according to the conceptions of researchers of the field of professional formation, that critically analyze the decrees 2208/97 and 5154/04, and denounce their frailty by creating integrated secondary education only as another option for articulation. It reports on the experience of building the Integrated Technical Dance Course, the Foundation for Technical School Support (FAETEC), its characteristics and main challenges, among which is teacher resistance. It concludes that only through the joint effort between teachers, coordinators and educational institutions, to valorize the diverse sources of knowledge that can emanate from the teaching experience, will be possible the curricular integration from the perspective of the Unitary School, ideological base that supports the conception of this modality education.
\end{abstract}

Keywords: Technical Course in Dance. Curricular Organization. Unitary School. Significant Learning. Teacher Knowledge. 


\section{INTRODUÇÃO}

Experiência é qualquer ação na qual o indivíduo se envolve e sai transformado; nela os indivíduos estão marcados por saberes, poderes e sujeitos. (Foucault, 2012).

A importância da experiência humana tem recebido destaque nas discussões historiográficas nos últimos anos, dando visibilidade aos sujeitos anônimos da história, que agora tem o reconhecimento do seu poder de transformação da sociedade (RÈMOND, 2003; THOMPSON, 1998; FOUCAULT, 2012). Daí a relevância deste relato.

Como membro da equipe técnico-pedagógica da Fundação de Apoio à Escola Técnica (FAETEC) por vinte anos, a autora deste artigo vivenciou a experiência da implantação de matrizes integradas no ensino profissional de nível médio desta rede de ensino, mais especificamente a do Curso Técnico em Dança, da Escola Técnica Estadual Adolpho Bloch (ETEAB), localizada no bairro de São Cristóvão (Rio de Janeiro/RJ).

Foram realizadas algumas reuniões na unidade escolar no ano de 2010, com o objetivo de ouvir os professores, sujeitos deste processo, na busca da criação de propostas e remoção de possíveis entraves, a fim de viabilizar a integração entre o ensino médio e o técnico. Foram reuniões conturbadas e de difícil conciliação. As respostas a um questionário aplicado ajudaram na compreensão dos motivos de resistência, ao sinalizarem como entraves: a) preocupação com a redução da carga horária do ensino médio; b) integração insuficiente entre equipes de ensino médio e técnico; c) a queixa de que a abordagem do assunto não havia atingido o resultado esperado e necessário.

As respostas obtidas poderiam gerar relevantes estudos sobre questões relacionadas ao trabalho docente e seu cotidiano, as forças de resistência que se processam no interior das instituições escolares, a precarização do trabalho docente, a falta de tempo para discussões das políticas públicas que minimizam a autonomia da escola, dentre outras. Apesar das inquietações apontadas, e pouco discutidas, atualmente todo o ensino médio profissional ofertado ao público dos turnos matutino e vespertino da rede em questão, encontra-se na modalidade integrada.

Este artigo intenta apresentar as características do curso Técnico em Dança da ETE Adolpho Bloch, como foi concebido, e conhecer as estratégias utilizadas por sua coordenadora na busca da integração entre os diversos componentes curriculares, tanto da formação geral quanto da técnica. O curso é considerado, segundo a coordenadora, o primeiro curso técnico de dança integrado da rede pública brasileira, e possivelmente da América Latina.

Julga-se relevante o relato deste processo, porque os saberes dos professores são pouco compartilhados e não são comparados com os outros no ambiente institucional. Como "combatentes solitários”, expressão cunhada por Perrenoud (2001, p. 164), os professores não falam do que sabem fazer. Assim também pensa Nóvoa (1992, p. 26), para quem "a organização das escolas parece desencorajar um conhecimento profissional partilhado dos professores, dificultando o investimento das experiências significativas”.

O artigo compreende inicialmente reflexões sobre a relação entre Trabalho e Educação, a partir das contribuições de Saviani (2007) especialmente, sendo discutidas em seguida as principais concepções e desafios na implantação do ensino médio integrado nas escolas técnicas, tendo como base referencial Frigotto, Ciavatta e Ramos (2005), Leal Neto (2010) e Cêa (2007), bem como os decretos e leis que sustentam as mudanças implementadas. No segundo momento será estudado o caso do curso Técnico em Dança, da Escola Adolpho Bloch (FAETEC), em que sua coordenadora relata a experiência de sua concepção, suas características, a estrutura curricular, e principais desafios. Por fim, reflete-se sobre a mobilização do saber docente, que consiste no maior desafio apontado pela coordenadora entrevistada, para a articulação interna desta modalidade de ensino.

Neste processo, a experiente profissional de dança e professora Rosane Campello mobilizou suas competências e saberes, construídos ao longo de anos. Para Perrenoud (2001), manifestar competências profissionais diante de uma situação complexa é ser capaz de identificar os obstáculos, considerar diversas estratégias, optar 
pela "menos ruim”, planejar e implementar a estratégia adotada, coordenar a implementação, reavaliar a situação e se necessário mudar a estratégia, cooperando com os outros profissionais; sempre extraindo ensinamentos e documentando as operações e as decisões.

\section{FUNDAMENTAÇÃO TEÓRICA}

\section{1 Relação entre Trabalho e Educação}

A existência humana não se constitui de uma dádiva natural garantida pela natureza, mas sim pela produção do próprio homem, porque o homem precisa aprender a produzir a própria existência, e é nesse processo que ele se forma, se constrói. Deste modo, é possível compreender que a educação é tão antiga quanto a existência humana e que sustenta uma relação de identidade com o processo de trabalho, pois é no próprio ato de produzir que os homens aprendem (SAVIANI, 2007).

A escola tradicional sempre pretendeu educar separando o homem dirigente do homem produtor, separando os que estavam destinados ao conhecimento da natureza e da produção, daqueles a quem eram entregues as tarefas de execução. Para Gramsci (apud Ciavatta, 1993, p. 8), muitos séculos se passaram até que se recuperasse "a perspectiva unitária da formação do homem político e produtor ao mesmo tempo,... [que] liberado da unilateralidade e restrição de seu ofício particular, pudesse converter-se de novo em político”.

Gramsci (2001) vê na educação uma dimensão estratégica na luta pela transformação da sociedade e apresentou o projeto da Escola Unitária para organizar a cultura no mundo capitalista. O "princípio unitário" relaciona-se à luta pela igualdade social, para a superação das divisões de classe que separam a sociedade entre governantes e governados. Ao delinear o programa escolar que deveria servir de guia para a organização de um centro de cultura integrado à luta ideológica para a conquista da hegemonia, Gramsci assinala que o princípio unitário ultrapassa a escola como instituição; significa o início de novas relações entre trabalho intelectual e trabalho industrial não apenas na escola, mas em toda a vida social.

Portanto, o trabalho é princípio educativo no ensino médio no sentido histórico, na medida em que proporciona a compreensão do processo histórico de produção científica e tecnológica, como conhecimentos desenvolvidos e apropriados socialmente para a transformação das condições naturais da vida e a ampliação das capacidades, das potencialidades e dos sentidos humanos; e, no sentido ontológico, o trabalho é princípio educativo na medida em que coloca exigências específicas para o processo educativo, visando à participação direta dos membros da sociedade no trabalho socialmente produtivo (RAMOS, 2008). ${ }^{2}$

Compreendendo o ensino médio integrado como fundamental para a construção de uma escola unitária, no sentido gramsciano, a seguir conheceremos os principais desafios apontados por pesquisadores de políticas públicas, para a sua implementação.

\section{2 Principais concepções e desafios na implementação do Ensino Médio Integrado - os decretos 2208/97 e 5154/04}

Segundo Leal Neto (2010) os dois mandatos de Fernando Henrique Cardoso (FHC) foram marcados por uma série de medidas neoliberais, das quais se podem destacar:

a. a redução da participação do Estado na economia com a privatização de diversas empresas estatais;

2 Ler mais sobre fundamentos ontológicos e históricos da relação Trabalho e Educação em: Saviani (2007), disponível em http://www.scielo.br/ pdf/rbedu/v12n34/a12v1234.pdf. 
b. a flexibilização e a desregulamentação do mercado de trabalho com a precarização legal da contratação de trabalhadores; e

c. a manutenção de altas taxas de juros ao lado da abertura ao capital financeiro internacional, com destaque para o capital volátil, especulativo.

Tais medidas contribuíram para o processo de subordinação do Brasil ao capital internacional e para o agravamento da sua dependência em relação aos centros hegemônicos do capitalismo.

No que tange às reformas de base educacionais, o governo FHC foi marcado por reprimir de forma sistemática as propostas da Lei de Diretrizes e Bases da Educação Nacional (LDB) 9394/96, discutidas durante anos por diversas organizações e instituições da sociedade civil preocupadas em gerar um projeto de educação de caráter democrático. Desde então, diferentes medidas legais foram sendo criadas sob a égide de um governo extremamente autoritário e que não apresentava nenhum projeto estável para a educação (FRIGOTTO, CIAVATTA e RAMOS, 2005, p. 13).

De todos os embates nas medidas tomadas durante o governo FHC, nenhuma delas retrocedeu tanto quanto a promulgação do Decreto n ${ }^{\circ}$ 2208/97, que serviu apenas para reforçar o dualismo existente na educação durante anos e que, baseado nos interesses de capital e mercado, evidenciou a "pedagogia das competências para a empregabilidade”, de acordo com as Diretrizes e Parâmetros Curriculares Nacionais. Se por um lado a LDB estabelece a formação profissional integrada à formação geral sob os aspectos humanísticos e científico-tecnológicos, o Decreto n ${ }^{\circ} 2208 / 97$ juntamente com a Portaria nº 646/97, vetaram a formação integrada, e regulamentaram formas fragmentadas e aligeiras de educação profissional em função das alegadas "necessidades do mercado”. ${ }^{3}$

O Decreto n ${ }^{\circ}$ 2208/97 definiu em seu artigo $5^{\circ}$ que a educação profissional de nível técnico deveria ter organização curricular própria e independente do ensino médio, impedindo qualquer possibilidade legal de integração curricular entre a educação profissional e o ensino médio, ou seja, entre formação geral e formação profissional. Nesse sentido, o decreto negou o Artigo no 39 da LDB 9394/96, que permitia essa possibilidade. Desta forma, a educação profissional de nível técnico a partir de então, só poderia ser oferecida de forma concomitante, com matrículas independentes, ou de forma subsequente para aqueles que já tivessem concluído o ensino médio. Portanto, o princípio da independência e não o da integração entre os cursos de ensino médio e os cursos de educação profissional estava na base da referida reforma (LEAL NETO, 2010). Para Cêa (2007, p. 7) este decreto desencadeou

o mais perverso efeito para os trabalhadores brasileiros: a desvinculação entre formação para o trabalho e elevação dos níveis formais de escolaridade permanece como a tendência predominante de (des)qualificação para o trabalho ofertada pelo sistema público de educação; ou seja, permanece a hegemonia da educação profissional desintegrada.

Mesmo apoiado política e juridicamente e apesar do comprometimento com os educadores, o governo do presidente Lula não revogou de imediato o Decreto no 2208/97. Segundo Frigotto, Ciavatta e Ramos (2005), em 2003, durante o seminário “Educação profissional: concepções, experiências, problemas e propostas” realizado em Brasília, forças políticas participantes interessadas na manutenção do Decreto ${ }^{\circ}$ 2208/97, alegaram, entre outros motivos, ser a LDB insuficiente para assegurar a diversidade de projetos criados a partir deste decreto. As discussões entre a sociedade civil e órgãos governamentais durante o seminário foram polêmicas e repletas de contradições e disputas teóricas e políticas que então revogaram o decreto anterior e deram origem ao Decreto n 5154, em julho de 2004.

Cabe ressaltar que apesar das alterações promovidas, o Decreto n ${ }^{0}$ 5154/04 não modificou completamente o anterior e, conforme Frigotto, Ciavatta e Ramos (2005), foi alvo de muita contestação. O novo Decreto manteve as possibilidades de articulação entre a educação profissional e o ensino médio nas modalidades concomitante 
e sequencial de cursos já previstas no decreto anterior e apresenta o ensino médio integrado apenas como "mais uma opção de articulação":

\begin{abstract}
A articulação entre a educação profissional técnica de nível médio e o ensino médio dar-se-á de forma: Integrada, oferecida somente a quem já tenha concluído o ensino fundamental, sendo o curso planejado de modo a conduzir o aluno à habilitação profissional técnica de nível médio, na mesma instituição de ensino, contando com matrícula única para cada aluno; concomitante (...) e subsequente (...). (Decr. $\mathrm{n}^{\circ} 5.154 / 04$, Art. $4^{\circ}$, § $1^{\circ}$, Incisos I, II,,III).
\end{abstract}

Outro aspecto identificado por Leal Neto (2010) nesse contexto, e que persistiu no segundo mandato do presidente Lula (2007-2010), se refere à permanência da lógica da independência, pois logo após a promulgação do Decreto 5154/04, houve a separação da Secretaria de Educação Básica (SEB), que ficou responsável pela política do ensino médio, e a Secretaria de Educação Profissional e Tecnológica (SETEC), que se tornou responsável pela política de educação profissional, ambas integrando o MEC. Tal medida torna ainda mais remota a possibilidade da oferta de uma Educação Unitária idealizada por Gramsci (2001).

Enfim, em resposta a diversas instituições de educação profissional e tecnológica que questionaram a aplicação do decreto 5154/04, o Parecer CNE/CEB nº 39/2004 estabelece que:

A instituição poderá adotar qualquer uma das três formas previstas no Decreto nº 5154/2004, na realidade, cinco, com o desdobramento em três da forma “concomitante”. O decreto não obriga, portanto, por uma ou outra, cabendo à instituição de ensino, no uso de sua autonomia, decidir pela forma que melhor se coaduna com sua proposta político-pedagógica. (Parecer CNE/CEB nº 39/2004, p.5).

Conclui-se, portanto, que não há nenhuma prioridade por parte das políticas públicas em oferecer o ensino médio integrado, uma vez que cabe às instituições de ensino decidir qual será o tipo de articulação a ser ofertada (CÊA, 2007).

\title{
3 PERCURSOS METODOLÓGICOS
}

\section{1 desafio da integração do Curso Técnico em Dança}

Por falta de prioridade das políticas públicas acima discutidas, desde o decreto até o ano de 2011, existiam somente quatro cursos de ensino médio integrado autorizados e com alunos matriculados na rede FAETEC: a) no ISERJ (Instituto Superior de Educação): Cursos Técnicos em Administração, em Informática e em Secretário Escolar; b) na ETEAB (Escola Técnica Estadual Adolpho Bloch): o Curso Técnico em Dança, autorizado a partir de 2011. Assim, pretende-se nesta seção discorrer sobre a origem deste último, compreender como se deu o processo de transformação de um grupo de dança em curso técnico integrado, conhecer suas características e desafios apontados por sua coordenadora.

Há mais de dez anos a ETEAB desenvolvia um trabalho contínuo na área da dança, através da Companhia de Atores Bailarinos Adolpho Bloch, coordenado pela professora Rosane Campello ${ }^{4}$. O grupo desenvolveu diversas oficinas de dança nas aulas de Educação Física, e atendeu ao longo deste período cerca de 700 alunos; alguns dos quais prosseguiram os estudos em cursos de pós-graduação em Dança, fazendo desta a sua profissão. A partir desse projeto bem-sucedido, a referida professora teve a iniciativa de construir uma proposta de curso Técnico em Dança na modalidade de ensino médio integrado, e trabalhou em sua elaboração por cerca de dois anos, considerando o aguardo dos trâmites legais. O curso veio a ser aprovado pelo Conselho Estadual de Educação do Rio de Janeiro e publicado no Diário Oficial de 28 de outubro de 2010, autorizado a funcionar a partir de 2011.

4 Rosane Laudano Campello Wanderley é professora da Escola Técnica Estadual Adolpho Bloch, licenciada em Educação Física, com pós-graduação Lato Sensu em Didática do Ensino da Dança e Metodologia do Ensino; é atriz bailarina e Maitre de Ballet. 
O primeiro concurso para o novo curso foi aberto no processo seletivo de 2010, para ingresso em 2011, oferecendo inicialmente vinte vagas, e não exigiu teste de habilidade específica para ingresso, pois, segundo a coordenadora Rosane, a proposta do curso consiste em formar profissionais da dança, intérpretes criadores, e não bailarinos profissionais. O curso tem a duração de 3 (três) anos, e é o primeiro da rede pública nessa modalidade a oferecer a matriz curricular integrada no Brasil, segundo suas pesquisas.

O curso tem como objetivo: "Desenvolver a formação profissional em Dança de forma integrada e significativa, capacitando para imediata inserção no mercado de trabalho”. Ao final do curso espera-se que o aluno esteja capacitado para criar propostas de entretenimento em clubes, associações diversas e espaços culturais, contribuindo para a formação de plateia e aumento da oferta cultural. Dois objetivos específicos propostos pelo curso estão diretamente relacionados à perspectiva da escola humanista: a) contemplar atividades integradoras de iniciação científica e no campo artístico cultural; b) despertar o interesse por questões sociais, políticas, artísticas, estéticas e ecológicas a partir da dança.

\section{2 Característica curriculares do Curso Técnico em Dança Integrado e os Desafios que se colocam ao trabalho docente}

A base teórica para a elaboração do curso Técnico em Dança, da FAETEC, compreende as proposições de Ausubel (1983), que partem da concepção de que os indivíduos apresentam uma organização cognitiva interna baseada em conhecimentos de caráter conceitual, e a sua complexidade depende mais das relações que esses conceitos estabelecem entre si, do que do número de conceitos presentes.

Nessa perspectiva, a coordenação do curso tem como objetivo pedagógico trabalhar com projetos anuais que desenvolvam a transdisciplinaridade e propor temas geradores que relacionem a dança com o trabalho, a ciência, a tecnologia e a cultura. Três etapas anuais consecutivas compõem a matriz curricular, cuja organização visa uma progressão pedagógica integrada que favoreça a aprendizagem e o aprimoramento prático característico do curso. Seguem abaixo os referenciais da estrutura curricular.

Tabela 1 - Referenciais Curriculares Nacionais da Educação Profissional de Nível Técnico da estrutura curricular do Curso Técnico em Dança

\begin{tabular}{|c|c|c|c|}
\hline FUNÇÃO & & SUB/FUNÇÕES & \\
\hline CRIAÇÃO & $\begin{array}{l}\text { 1.1. Elaboração e direção } \\
\text { coreográfica para dança e } \\
\text { teatro e criação de roteiros. }\end{array}$ & $\begin{array}{c}\text { 1.2. Composição e direção } \\
\text { coreográfica para musicais, } \\
\text { shows, TV, vídeo e cinema } \\
\text { e apresentações de releituras } \\
\text { (reinterpretações) de dança folclórica } \\
\text { e outras aplicações em dança. }\end{array}$ & $\begin{array}{l}\text { 1.3. Elaboração } \\
\text { de identidade } \\
\text { audiovisual } \\
\text { e espetáculos } \\
\text { e produções } \\
\text { em dança. }\end{array}$ \\
\hline EXECUÇÃO & $\begin{array}{l}\text { 2.1. Realização performancial de } \\
\text { dança profissional para grandes } \\
\text { grupos e companhias de dança. }\end{array}$ & $\begin{array}{l}\text { 2.2. Realização performancial } \\
\text { para as linguagens do musical, } \\
\text { shows, TV, vídeo e cinema. }\end{array}$ & \\
\hline PRODUÇÃO & $\begin{array}{l}\text { 3.1. Planejamento e pré-produção } \\
\text { em projetos de dança: identificação } \\
\text { e organização das ações e insumos. }\end{array}$ & & \\
\hline PRESERVAÇÃO & $\begin{array}{l}\text { 4.1. Identificação, preservação } \\
\text { e divulgação dos registros } \\
\text { da memória da dança. }\end{array}$ & & \\
\hline
\end{tabular}

Fonte: Plano do Curso Técnico em Dança da ETEAB/FAETEC (2010).

No quadro acima, com base nos Referenciais Curriculares Nacionais da Educação Profissional de Nível Técnico, a estrutura curricular do curso compreende as funções de Criação, Execução, Produção e Preservação. 
Seguindo os princípios da Escola Unitária de Gramsci, em que o princípio do trabalho visa formar dirigentes, as funções de Criação e Produção contemplam sub funções que favorecem aos alunos desenvolverem habilidades como sujeitos do processo, e não como meros executores. Este é um dos principais objetivos de uma educação para a emancipação, para a participação social, enfim, para a promoção de transformação, pela posição estratégica desses futuros profissionais.

Outra preocupação importante da proposta, observada na função Preservação, é desenvolver nos alunos a sensibilidade para com a história e a memória social, pois se História e Trabalho estão vinculados socialmente, é necessário lutar contra os apagamentos da memória social das instituições, das raízes que constituem os sujeitos e das relações sociais.

A Matriz Curricular do Curso Técnico em Dança é apresentada abaixo (Tabela 2), seguida da reflexão de alguns desafios que se colocam ao trabalho docente.

Tabela 2 - Matriz Curricular Integrada - Técnico em Dança (Artista Bailarino)

\begin{tabular}{|c|c|c|c|c|}
\hline Componentes Curriculares & $1^{a}$. sér. & $2^{\text {a }}$. ser. & $3^{\text {a }}$.sér. & Total \\
\hline Língua Portuguesa & 160 & 80 & 80 & 320 \\
\hline Artes & - & 80 & 80 & 160 \\
\hline Informática & - & 80 & - & 80 \\
\hline Língua Estrangeira & 80 & 80 & 80 & 240 \\
\hline Literatura & 80 & - & 80 & 160 \\
\hline Educação Física & 80 & 80 & - & 160 \\
\hline Matemática & 80 & 80 & 80 & 240 \\
\hline Física & 80 & 80 & 80 & 240 \\
\hline Química & 80 & 80 & 80 & 240 \\
\hline Biologia & 80 & 80 & 80 & 240 \\
\hline Geografia & 80 & 80 & 80 & 240 \\
\hline História & 80 & 80 & 80 & 240 \\
\hline Sociologia & 80 & 80 & 80 & 240 \\
\hline Filosofia & 80 & 80 & 80 & 240 \\
\hline Técnica de Dança I (Clássica) & 160 & - & - & 160 \\
\hline Consciência Corporal & 80 & - & - & 80 \\
\hline Fundamentos do Teatro & 80 & - & - & 80 \\
\hline Fundamentos da Música & 80 & - & - & 80 \\
\hline Técnicas de Dança II (Moderna) & - & 80 & - & 80 \\
\hline Introdução à Dança Contemporânea & - & 160 & - & 160 \\
\hline História da Dança & - & 80 & - & 80 \\
\hline Psicologia das Relações Humanas & - & 80 & - & 80 \\
\hline Técnica de Dança III (Jazz) & - & - & 80 & 80 \\
\hline Dança Contemporânea & - & - & 80 & 80 \\
\hline Vídeo Dança & - & - & 80 & 80 \\
\hline Produção Coreográfica & - & - & 80 & 80 \\
\hline Prática de Montagem & - & - & 160 & 160 \\
\hline Total & 1.440 & 1.440 & 1.440 & 4.320 \\
\hline
\end{tabular}

Fonte: Plano do Curso Técnico em Dança da ETEAB/FAETEC, 2010.

Segundo a coordenadora, o curso tem como diferencial o oferecimento de Língua Estrangeira para fins específicos, a qual se divide em Língua Francesa no primeiro ano, Língua Inglesa no segundo e Língua Espanhola no terceiro, garantindo o básico instrumental de cada língua e assim possibilitar aos bailarinos a participação em audições de dança internacionais. 
Observa-se na matriz curricular acima, que a base comum curricular nacional é oferecida nos três anos do curso, e que os componentes curriculares da formação técnica se distribuem igualmente nessas três etapas anuais, garantindo assim uma sólida formação, totalizando 4.320 horas.

A etapa prática do curso ocorre nos laboratórios da unidade escolar sob a orientação do professor, que conduz atividades com procedimentos técnicos e utilização de produtos, materiais e equipamentos da área, pressupondo intercâmbio permanente entre teoria e prática.

O curso possui ainda um Plano de Estágio Profissional Supervisionado, de caráter qualitativo e sem contagem de horas, que compreende o cumprimento de atividades ao término de cada etapa, bem como elaboração, ensaio e apresentação dos projetos registrados na ficha individual dos alunos. Em cada etapa há previsão de pelo menos duas visitas técnicas ao Centro Coreográfico da Cidade do Rio de Janeiro, ao Teatro Municipal, ao Departamento Corporal da UFRJ, à Faculdade Angel Viana, ao Centro Universitário da Cidade (Campus Ipanema - setor de Dança), ao Paço Imperial, ao Centro Cultural Banco do Brasil e à Academia Brasileira de Letras.

A mera composição de uma estrutura curricular e avaliativa unindo componentes disciplinares de formação geral e técnica, não é o suficiente para garantir a integração entre as mesmas. O processo de integração consiste num processo mais complexo e desafiante.

\section{RESULTADOS E DISCUSSÃO}

\section{1 A mobilização do Saber Docente - difícil tarefa}

Por se tratar de um curso diferenciado, que articula disciplinas específicas da área de Dança e conhecimentos gerais, muitos são os desafios na construção de saberes necessários aos docentes envolvidos. Diante da complexidade do todo e das particularidades da educação profissional, o docente que atua no ensino médio integrado deve saber integrar os conhecimentos científicos, tecnológicos, sociais e humanísticos, que compõem o núcleo comum de conhecimentos gerais e universais e os conhecimentos e habilidades relativas às atividades técnicas de trabalho e de produção do curso técnico.

Assim, o perfil do docente atuante na educação profissional deve abranger os seguintes graus de complexidade: desenvolver a capacidade de usar, nível mais elementar, relacionado à aplicação dos conhecimentos ao emprego das habilidades instrumentais; desenvolver a capacidade de produzir, que requer o uso de conhecimentos e habilidades necessários à concepção e execução de objetivos para os quais as soluções tecnológicas existem e devem ser adaptadas; e desenvolver a capacidade de inovar, nível mais elevado de complexidade, relacionado às exigências do processo de geração de novos conhecimentos e novas soluções tecnológicas. ${ }^{5}$

Afirma a professora Rosane Campello que o processo de execução da matriz integrada tem sido árdua tarefa. A resistência de alguns professores e profissionais envolvidos acaba dificultando o bom andamento do curso, por não se mostrarem dispostos a integrar conteúdos e trabalhar com Aprendizagem Significativa; requisito fundamental para que o ensino médio integrado contribua na formação de profissionais atuantes e promotores de transformação social. É possível que tal resistência tenha raízes na própria formação inicial desses profissionais, capaz de gerar insegurança na promoção de mudanças. Portanto, a formação continuada dos professores que atuam nessa modalidade de ensino coloca-se como fator preponderante para o sucesso da integração, visto que deste profissional espera-se:

a capacidade de elaboração de estratégias, estabelecimento de formas criativas de ensino-aprendizagem; pressuposição de condições necessárias para o desenvolvimento da educação profissional de acordo com suas peculiaridades, particularidades e contextualização. ${ }^{6}$

5 Plano do Curso Técnico em Dança (2010).

6 Idem. 
Para essa capacitação em serviço, é necessário um esforço conjunto entre a coordenação, a gestão da unidade escolar, a Diretoria de Ensino de cada instituição, e a iniciativa docente. Enfim, é um trabalho que requer intencionalidade e frequência; que nem sempre é produzido com as ferramentas e o aprofundamento necessários.

\section{2 Alternativas Possíveis}

A experiência deste estudo demonstra ser insuficiente a busca de uma integração do ensino médio e profissional voltada somente para ajustes de carga horária e seleção de componentes curriculares. Para que o projeto de educação unitária alcance seu fim, como possibilidade de superação da divisão humana em decorrência da "divisão social do trabalho, superando a redução da preparação para o trabalho ao aspecto operacional, simplificado, livre dos conhecimentos na sua origem científico-tecnológica e na sua apropriação histórico-social”7 , faz-se necessário pensar nas articulações internas do processo (didático-pedagógicas), que envolvem a instituição e os seus sujeitos.

Uma alternativa que desponta como bem-sucedida, a partir da vivência profissional da autora, consiste no investimento na profissionalização docente, bem como da equipe técnico-pedagógica e diretiva. Evocam-se aqui três autores que discutem a questão da profissionalização docente: Nóvoa (1992), Tardif (2002) e Perrenoud (2001), que caracterizam o saber docente composto por vários saberes provenientes de diferentes fontes: disciplinares, curriculares, profissionais e experienciais. ${ }^{8}$

Os três autores têm em comum o reconhecimento de que o contexto em que o profissional atua deve se modificar, a cultura das instituições deve ser considerada e deve-se buscar uma verdadeira parceria entre professores, universidades formadoras e responsáveis pelo sistema educacional, para que o desenvolvimento de uma verdadeira profissionalização do professor seja realidade. Somente através deste esforço conjunto, valorizando as diversas fontes de saber que podem emanar da experiência docente, será possível a integração curricular na perspectiva da Escola Unitária, base ideológica que sustenta a concepção do ensino médio integrado.

\section{AGRADECIMENTOS:}

À professora Rosane Campello, por sua colaboração na reconstrução e divulgação desta experiência.

\section{REFERÊNCIAS:}

AUSUBEL, D. P.; NOVAK, J. D., HANESIAN, H. Psicología Educativa: un punto de vista cognoscitivo. México: Trillas, 1983.

BRASIL. Decreto nº 2208/1997. Disponível em: www.planalto.gov.br/ccivil_03/decreto/D2208.htm - Acessado em: 15.05.2011.

BRASIL. Decreto no 5154/2004. Disponível em: http://www.planalto.gov.br/ccivil_03/_Ato2004-2006/2004/ Decreto/D5154.htm\#art9. SimilaresAcessado em: 15.05.2011.

7 Cf. Frigotto, Ciavatta e Ramos (2005, p. 85).

8 Com relação à profissionalização docente, a proposta de Nóvoa é focada na valorização de pessoas e grupos, e é mesclada com outras tendências como: reflexão na ação, método clínico e investigativo. Tardif faz considerações relevantes sobre os saberes experienciais, dos quais devem se apropriar os educadores, no sentido de objetivá-los junto aos pares, e assim ter o controle social sobre os mesmos. Para Perrenoud, o professor deve manifestar competências profissionais diante de situações complexas; a explicitação e a clarificação dessas competências para a sociedade podem conferir maior grau de profissionalização ao professor. 
BRASIL. Lei de Diretrizes e Bases da Educação Nacional (LDB) 9394/1996. Disponível em: http://www. planalto.gov.br/ccivil_03/Leis/L9394.htm. Acessado em: 28.05.2011.

BRASIL. Portaria MEC nº 646/97 - de 14 de maio de 1997. MEC - Ministério da Educação Disponível em: http://portal.mec.gov.br/setec/arquivos/pdf/PMEC646_97.pdf. Acessado em: 15.05.2011.

CÊA, G. S. S. A reforma da educação profissional e o ensino médio integrado: perspectivas, tendências e riscos. $\mathrm{O}$ estado da arte da formação do trabalhador no Brasil: pressupostos e ações governamentais a partir dos anos 1990. $1^{\text {a }}$. ed. Cascavel: Edunioeste, 2007, v. 1, p. 133-156.

CIAVATTA, Maria F. A escola do trabalho: história e imagens. Tese de Doutorado, UFF, Niterói, 1993.

CONSElHO ESTAduAl DE EDUCAÇÃO. Plano do Curso de Educação Profissional Técnica de Nível Médio, no Eixo Tecnológico de Produção Cultural e Design, com Habilitação Técnica em Dança da Escola Técnica Estadual Adolpho Bloch, da Fundação de Apoio à Escola Técnica/FAETEC. Aprovado pelo Parecer CEE nº 158 de 31 de agosto de 2010.

FOUCAULT, Michel. A arqueologia o saber. 8a. edição, Ed. Forense Universitária, 2012.

FRIGOTTO, Gaudêncio; CIAVATTA, Maria; RAMOS, Marise (org.). Ensino médio integrado: concepções e contradições. São Paulo: Cortez, Fund. Oswaldo Cruz, 2005.

GRAMSCI, A. Cadernos do cárcere. Os intelectuais. O princípio educativo. Jornalismo. Volume 2, Rio de Janeiro: Civilização Brasileira, 2001.

LEAL NETO, A. A. V. A. Educação Profissional integrada ao Ensino Médio no governo Lula: uma análise à luz da categoria trabalho. Dissertação de Mestrado, UFBA, 2010. Disponível em: http://www.bibliotecadigital.ufba.br/tde_busca/arquivo.php?codArquivo=3864

NÓVOA, Antônio. Formação de professores e formação docente. In: NÓVOA, Antônio. Os professores e a sua formação. Lisboa: Publicações Dom Quixote, 1992. p. 15-33.

PERRENOUD, Philippe. A ambiguidade dos saberes e da relação com o saber na profissão de professor. In: PERRENOUD, Philippe. Ensinar: agir na urgência, decidir na incerteza. Porto Alegre: Artmed, 2001. p. 135-193.

RAMOS, Marise Nogueira. Concepção do ensino médio integrado. Disponível em: http://www.iiep.org.br/ curriculo_integrado.pdf (2008). Acessado em: 12.04.2011.

RÉMOND, René. Uma história presente. In: (Org.). Por uma história política. 2a . edição. Rio de Janeiro: FGV, 2003. p. 13-36.

SAVIANI, Dermeval. Trabalho e educação: fundamentos ontológicos e históricos. In: Revista Brasileira de Educação. UNICAMP, v. 12, nº 34, Jan/Abr, 2007. Campinas: 2007. (pp. 152-165). Disponível em: http://www. scielo.br/pdf/rbedu/v12n34/a12v1234.pdf.

TARDIF, Maurice. Saberes docentes e formação profissional. Petrópolis: Vozes, 2002.

THOMPSON, E. P. Costumes em comum. São Paulo, Companhia das Letras, 1998. 